\title{
Association between genetic polymorphisms of the IL28B gene and leukomonocyte in Chinese hepatitis B virus-infected individuals
}

\author{
Yuzhu Song ${ }^{1}$, Yunsong Shen ${ }^{2}$, Xueshan Xia ${ }^{1}$, A-Mei Zhang ${ }^{\text {Corresp. } 1}$ \\ 1 Faculty of Life Science and Technology, Kunming University of Science and Technology, Kunming, Yunnan, China \\ 2 First People's Hospital of Yunnan Province, Kunming, Yunnan, China \\ Corresponding Author: A-Mei Zhang \\ Email address: zam1980@yeah.net
}

Background: Hepatitis B infection is one of the most severe hepatic diseases in China. Thus, understanding the genetic pathogenesis of hepatitis B virus (HBV)-infected individuals is important. Although no consistent result is obtained in different populations, HBV treatment effect is reportedly associated with the IL28B gene. Methods: To investigate the role of the IL28B gene in HBV-infected individuals in Yunnan, China, we screened genotypes of three single nucleotide polymorphisms (SNPs, rs12979860, rs8099917, and rs12980275) in HBV-infected individuals and general controls by using SnapShot and sequencing. Results: Results showed no significant difference was found in genotypes, alleles, and haplotypes frequency between the HBV-infected individuals and controls. After dividing the HBV-infected individuals into patients in acute infection, chronic HBV patients, and patients undergoing convalescence, the genotype GT $(P=0.033)$ and allele $\mathrm{G}(P=0.038)$ of rs8099917 showed statistically higher frequency in the acutely infectious individuals than in the HBV patients undergoing convalescence. HBV viral load was higher in the acutely infectious patients than in the chronic infection group. Strikingly, we found that leukomonocyte (LYM) level was associated with SNPs in the IL28B gene. In addition, the LYM levels were lower in the HBV-infected individuals with genotype CC of rs12979860 and AA of rs12980275 than in the patients with other genotypes of these two SNPs. Conclusion: Our results suggested genetic polymorphisms of the IL28B gene were associated with LYM level of HBV-infected individuals. 
1 Association between genetic polymorphisms of the $I L 28 B$ gene and leukomonocyte in

\section{Chinese hepatitis B virus-infected individuals}

3 Yuzhu Song 1, Yunsong Shen ${ }^{2}$, Xueshan Xia ${ }^{1}$, A-Mei Zhang 1,*

$4{ }^{1}$ Faculty of Life Science and Technology, Kunming University of Science and Technology,

5 Kunming, Yunnan, China

$6 \quad 2$ First People's Hospital of Yunnan Province, Kunming, Yunnan, China

7

8

9

$10 *$ Corresponding author

11 Dr. A-Mei Zhang, Molecular virus Units, Faculty of Life Science and Technology, Kunming

12 University of Science and Technology, Kunming, Yunnan 650500, China. Tel/Fax: 86-871-

13 65920756; E-mail: zam1980@yeah.net 


\section{Abstract}

Background: Hepatitis B infection is one of the most severe hepatic diseases in China. Thus, understanding the genetic pathogenesis of hepatitis B virus (HBV)-infected individuals is important. Although no consistent result is obtained in different populations, HBV treatment effect is reportedly associated with the $I L 28 B$ gene.

Methods: To investigate the role of the $I L 28 B$ gene in HBV-infected individuals in Yunnan, China, we screened genotypes of three single nucleotide polymorphisms (SNPs, rs 12979860, rs8099917, and rs12980275) in HBV-infected individuals and general controls by using SnapShot and sequencing.

Results: Results showed no significant difference was found in genotypes, alleles, and haplotypes frequency between the HBV-infected individuals and controls. After dividing the HBV-infected individuals into patients in acute infection, chronic HBV patients, and patients undergoing convalescence, the genotype GT $(P=0.033)$ and allele $\mathrm{G}(P=0.038)$ of rs 8099917 showed statistically higher frequency in the acutely infectious individuals than in the HBV patients undergoing convalescence. HBV viral load was higher in the acutely infectious patients than in the chronic infection group. Strikingly, we found that leukomonocyte (LYM) level was associated with SNPs in the $I L 28 B$ gene. In addition, the LYM levels were lower in the HBVinfected individuals with genotype CC of rs12979860 and AA of rs12980275 than in the patients with other genotypes of these two SNPs.

Conclusion: Our results suggested genetic polymorphisms of the IL28B gene were associated with LYM level of HBV-infected individuals. 


\section{Introduction}

Although hepatitis B virus (HBV) vaccine is widely used, HBV infection remains a main cause of hepatic cirrhosis and hepatocellular carcinoma (2012). Among 2 billion people infected with HBV, 350 million individuals develop chronic HBV infection (Liaw Y. F. and Chu C. M. 2009). Over $8 \%$ of Chinese, Southeast Asian, and African populations are hepatitis B surface antigen (HBsAg)-positive (Trepo C., Chan H. L. and Lok A. 2014), so HBV infection is still a serious problem in these populations. Genetic factors influence HBV-infection and treatment effects of HBV-infected individuals (Hu L. et al. 2012; Li S. et al. 2012; Wasityastuti W. et al. 2016). Understanding the role of host genetic variations in HBV infection, pathogenesis, and therapy is important to provide individualized protection and treatment for HBV-infected cases.

Interleukin 28B (IL28B) belongs to the interferon $\lambda$ family, which is a new interferon family. Genetic variations of the $I L 28 B$ gene have been identified to be associated with HCV infection, viral clearance, and response to therapy (Suppiah V. et al. 2009; Tanaka Y. et al. 2009; Thomas D. L. et al. 2009; Zhang A.-M. et al. 2014). However, genome-wide association studies (GWAS) in Asian population found that IL28B gene is not correlated with HBV infection or viral clearance (Kamatani Y. et al. 2009; Hu Z. et al. 2013). Kamatani et al. identified that genetic variants in the HLA-DP locus are strongly associated with risk of persistent HBV infection (Kamatani Y. et al. 2009). Subsequently, two new gene loci (HLA-C and UBE2L3) have been highlighted to play important roles in the clearance of HBV infection (Hu Z. et al. 2013). However, the single nucleotide polymorphisms (SNPs) or the haplotypes constructed by SNPs in the $I L 28 B$ gene can influence the HBV infection, HBV surface antigen seroclearance, or 
57 treatment of HBV-infected individuals in special cohorts (Seto W. K. et al. 2013; Domagalski K. et al. 2014). SNPs rs12979860 and rs8099917 were mostly studied and identified to be associated with HBV-infection in Chinese (Chen J. et al. 2015). Until now, we found no study was performed to reveal the relationship of genetic polyporphisms in the $I L 28 B$ of HBV infected persons and biochemical characteristics. The purpose of this study is to investigate whether SNPs in the $I L 28 B$ gene influence the HBV infection and biochemical characteristics of HBV-infected individuals in Yunnan, China.

\section{Materials and methods}

\section{Subjects}

All HBV infected individuals and age- and gender-matched controls were recruited by doctors in the First People's Hospital of Yunnan Province. In our pervious study, basic information, biochemical characteristics, and HBV serological markers of each subject were reported (Song Y. et al. 2016). In brief, The liver function test [alanine transaminease (ALT), aspartate transaminase (AST), total bilirubin (TBIL), direct bilirubin (DBIL), indirect bilirubin (IBIL), total protein (TP), albumin (ALB), and globin (GLOB)], renal function [blood urea nitrogen (BUN), serum creatinine (CREA), serum uric acid (UA), and blood glucose (GLU)], and part of blood routine [white blood cells (WBC), neutrophilic granulocyte (NEUT), lymphocytes (LYM), monocytes (MONO), eosinophil granulocyte (EO), and basophile granulocyte (BASO)] were measured (All data has been reported in our previous study, Song Y. et al. 2016). All individuals were Han Chinese. In this study, whole blood samples (3 mL) of 493 
HBV-infected individuals (274 males and 219 females) and 460 controls (285 males and 175

females) were collected. All HBV-infected individuals and controls were not infected with hepatitis C virus (HCV), human immunodeficiency virus (HIV), and Treponema pallidum. All controls were devoid of HBV, HCV, or HIV infection, and no seriously hepatitic disease (hepatic fibrosis, Hepatocellular Carcinoma, and so forth) were identified in controls. The mean ages of the individuals in the HBV-infected and control cohorts were $41.5 \pm 0.3$ and $38.8 \pm 0.3$ years (mean $\pm \mathrm{SEM}$ ), respectively. HBV-infected individuals were also without other serious liver disease. Written informed consent conforming to the tenets of the Declaration of Helsinki was obtained from each participant prior to the study. This study was approved by the Institutional Review Board of Kunming University of Science and Technology (Approval No. 2014SK027).

\section{Genomic DNA extraction and genotyping}

Genomic DNA was extracted from whole blood by using the TIANamp genomic DNA Kit (TIANGEN, China). Three SNPs (i.e., rs12979860, rs8099917, and rs12980275) in the IL28B gene were selected and analyzed as reference-described (Chen J. et al. 2015). Genotypes of each SNP were screened by using SnapShot assay (Table S1). SnapShot is based on single base extension. In brief, amplifying and extending primers for each SNP are firstly designed. Then

PCR reaction is performed with two kinds of primers and will be terminated behind one base of

3' end of extending primers. Finally, genotypes of each SNP are determined according to fluorescence color. Genotyping results of $10 \%$ total samples were verified by sequencing. Haplotypes were constructed using Phase software for further analysis (Stephens M. and 
Donnelly P. 2003).

\section{Subgrouping of HBV infected individuals}

According to the subgrouping principle in our previous study (Song Y. et al. 2016), HBV infected individuals were divided into three groups. Group \#1 included patients who with HbsAg and $\mathrm{HBeAg}$ positive were at acute infected phase $(N=29)$. Group \#2 included patients with HBsAg and anti-HBc positive, who were at chronic infected phase $(N=202)$. Patients in group \#3 were comprised of HBV-infected individuals undergoing convalescence $(N=262)$, who were anti-HBc positive but HBV DNA negative.

\section{Quantification of the HBV viral load}

HBV DNA was extracted from the serum of each sample by using the TIANamp Virus DNA/RNA Kit (TIANGEN, China). The HBV viral load in the serum of $59 \mathrm{HBV}$ infected individuals was detected by using the Hepatitis B Viral DNA Quantitative Fluorescence Diagnostic Kit (realtime-PCR-Fluorescence Probing) (Sansure, China) in accordance with the manufacturer's instructions and ABI 7500 Fast Real-Time PCR system (Applied Biosystems, USA). Results were recorded in International Unit (IU)/mL; one IU/mL was equivalent to 5.6 copies/mL. The lowest detection limitation of this quantitative method was 2800 copies $/ \mathrm{mL}$ (500 $\mathrm{IU} / \mathrm{mL})$. In further analysis, HBV DNA was $\log 10$-transformed, i.e., the lowest detection limitation was $3.45 \log 10$ copies $/ \mathrm{mL}$. 
120

121

122

124

125

126

127

128

129

130

131

132

133

134

135

136

137

138

139

140

\section{Data analysis}

The Hardy-Weinberg equilibrium (HWE) was assessed in each variant to evaluate the deviation of collected cohorts. Given that the numbers of a genotype of each SNP were less than five, 1000 iterations for simulation were performed. The Chi-square test was collected to analyze the frequency of genotypes and alleles between the different cohorts. Student's $t$-test (unpaired, two tails) was used to compare HBV viral load between the two HBV-infected groups and biochemical characteristics among the HBV infected individuals with different genotypes.

Biochemical characteristics in the groups are presented as mean $\pm \mathrm{SEM}$. Correlation analysis was used to analyze the relationship between viral loads and LYM levels. Statistical significance was considered at $P<0.05$.

\section{Results}

No deviation was found in the HBV infected individuals and controls after calculating HWE, and these results suggested that the analyzed population was in genetic equilibrium. Genotype and allele frequency showed no significant difference between the HBV-infected individuals and general controls (Table 1). The genotyping data are listed in Supplementary Tables 2 and 3 (Table S2 for HBV-infected patients and Table S3 for controls). Seven and five haplotypes constructed by three SNPs were identified in the HBV-infection group and controls, respectively. Although the haplotypes were somewhat different between two groups, the frequency of each haplotype showed no significant difference (Table 2).

HBV-infected individuals were divided into three subgroups according to HBV serological 
141

142

143

144

145

146

147

148

149

150

151

152

153

154

155

156

157

158

159

160

161

markers of patients. Excluding the genotype and allele frequency of SNP rs8099917 between groups \#1 and \#3, we identified no other significant difference (Table 3). The genotype GT of rs8099917 showed a statistically higher frequency in group \#1 $(20.69 \%, 6 / 29)$ than in group \#3 $(8.40 \%, 22 / 262)(P=0.033)$, whereas the genotype TT of rs 8099917 showed a significantly low frequency in group $\# 1(P=0.033)$. The frequencies of allele $\mathrm{G}$ were $10.34 \%$ and $4.20 \%$ in patients of group \#1 and of group \#3, respectively. Hence, allele G likely seemed the risk factor for patient in group \#1 (Table 3).

Given that the patients in group \#3 underwent convalescence, HBV DNA viral load cannot be detected in this study. The HBV viral loads of 14 acutely and 44 chronic HBV-infected individuals were tested. The results showed that HBV viral load of the acutely HBV-infected individuals was higher than that of the chronic HBV-infected group $(P=0.0003)$ (Fig. 1). The viral loads of the patients with different genotypes of each SNP were similar in groups \#1 and \#2. Considering that the frequencies of genotype CC of rs12979860, GG of rs8099917, and GG of 12980275 were minor in our two cohorts (HBV-infected individuals and controls), we pooled genotypes CC and CT of rs12979860, genotypes GG and GT of rs8099917, and genotypes GG and AG of rs12980275 for further biochemical characteristics analysis (Table 4). Results showed that leukomonocyte (LYM) levels existed discrepancies between two groups of SNPs rs 12979860 and rs12980275. The LYM levels of the HBV-infected individuals with genotype CC of rs $12979860(P=0.032)$ and genotype AA of rs $12980275(P=0.034)$ were significantly lower than that of the patients with pooled genotypes. No correlation was found between HBV viral load and LYM level. 
163

164

165

166

167

168

169

170

171

172

173

174

175

176

177

178

179

180

181

182

\section{Discussion}

IL28B plays an important role in HCV infection and fateful hepatic diseases caused by

HCV (Patin E. et al. 2012; Thompson A. J. et al. 2012). Although no association exists between HBV infection and genetic polymorphisms in the $I L 28 B$ gene by GWAS, the $I L 28 B$ gene could influence the viral clearance and treatment effect in different HBV-infected populations (Stattermayer A. F. and Ferenci P. 2015). In present study, we analyzed the genotype and allele frequency of SNPs in the $I L 28 B$ gene, district phases of HBV infection, HBV viral load, and biochemical characteristics of HBV infected individuals.

SNPs rs12979860, rs8099917, and rs12980275 were frequently studied in HBV-infected populations (Li W. et al. 2011; Martin-Carbonero L. et al. 2012). Although analysis results were not confident, the important role of $I L 28 B$ could not be neglected. In present study, we did not identify the association between the genotypes and alleles of three SNPs and HBV infection. However, the genotypes of rs 8099917 were likely different between HBV-infected individuals under the acute infected phase and convalescence. This result suggested that genetic variations of the $I L 28 B$ gene mignt influence HBV-infected phase. Considering that the HBV viral load was detected in only $58 \mathrm{HBV}$ infected individuals, we did not identify the association between HBV viral load and SNP genotypes in the $I L 28 B$ gene. However, polymorphisms of the IL28B gene were reportedly associated with HBV viral load and liver inflammation (Li W. et al. 2011). HBV-infected sample size should be amplified for further study. Genetic polymorphisms in the $I L 28 B$ gene were reported not to affect HBV viral clearance 
183 in HBV-infected or HBV/HIV-coinfected persons (Sungkanuparph S. et al. 2004). Although the

184 effect of the $I L 28 B$ gene is unclear in $\mathrm{HBV} / \mathrm{HCV}$-coinfected persons, HBV viral load and/or viral

185 clearance might be influenced (De Re V. et al. 2016) because of the affirmatory role of IL28B in

186 HCV infection (Ge D. et al. 2009; Thomas D. L. et al. 2009). To exclude the effect of coinfection,

187 we selected persons infected by HBV only and confirmed that genetic variations of the IL28B

gene might relate to the pathogenesis of $\mathrm{HBV}$ infection and biochemical characteristics of HBVinfected individuals.

HBV viral load was detected in 58 HBV infected individuals, including 14 acutely and 44

chronic infectious patients. The viral load was significantly higher in acute infectious group than

in chronic group. However, no association was found between HBV viral load and genetic

variations in the $I L 28 B$ gene. Similarly, no correlation was found between HBV viral load and

LYM level. These results suggested that the association between genetic polymorphisms and

LYM might not be influenced by HBV viral load. Whether HBV genotype played a special role in the association needs further study.

LYM is one of the most important immune cells, which main function is to recognize and clear the bacteria, virus, and tumor. When individuals are infected by virus, LYM will be activited and induce a series of immune response. Due to the lack of analysis between LYM level and genetic polymorphisms in HBV-infected patients, we firstly performed and identified that the LYM level showed significant difference between HBV patients with differ genotyopes of SNPs rs12979860 and rs12980275. Although the results needs further verifivation, it would help us to explore the role of LYM in HBV infection. 
205

206

207

208

209

210

211

212

213

214

215

216

217

218

219

220

221

222

223

224

5

\section{Conclusion}

No association was found between genetic variations in the IL28B gene and HBV infection in the Yunnan population. However, LYM level could be influenced by genetic variations in the IL28B gene in this study. Further complex analyses should focus in studying the relationship between host genetic factors, biochemical characteristics of HBV patients, HBV infection, HBVinfected process, HBV viral load, and HBV genotypes.

\section{Acknowledgements}

We thank all participants in this study.

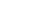

\section{References}

2012. EASL clinical practice guidelines: Management of chronic hepatitis B virus infection. $J$ Hepatol 57: 167-185.

Chen J., Wang W., Li X. and Xu J. 2015. A meta-analysis of the association between IL28B polymorphisms and infection susceptibility of hepatitis B virus in Asian population. $B M C$ Gastroenterol 15: 58.

De Re V., De Zorzi M., Caggiari L., Lauletta G., Tornesello M. L., Fognani E., Miorin M., Racanelli V., Quartuccio L., Gragnani L., Russi S., Pavone F., Ghersetti M., Costa E. G., 
Casarin P., Bomben R., Mazzaro C., Basaglia G., Berretta M., Vaccher E., Izzo F., Buonaguro F. M., De Vita S., Zignego A. L., De Paoli P. and Dolcetti R. 2016. HCVrelated liver and lymphoproliferative diseases: association with polymorphisms of IL28B and TLR2. Oncotarget 7: 37487-37497.

Domagalski K., Pawlowska M., Zalesna A., Tyczyno M., Skorupa-Klaput M., Tretyn A. and Halota W. 2014. The relationship between IL-28B polymorphisms and the response to peginterferon alfa-2a monotherapy in anti-HBe-positive patients with chronic HBV infection. Eur J Clin Microbiol Infect Dis 33: 2025-2033.

Ge D., Fellay J., Thompson A. J., Simon J. S., Shianna K. V., Urban T. J., Heinzen E. L., Qiu P., Bertelsen A. H., Muir A. J., Sulkowski M., McHutchison J. G. and Goldstein D. B. 2009. Genetic variation in IL28B predicts hepatitis C treatment-induced viral clearance. Nature 461: 399-401.

Hu L., Zhai X., Liu J., Chu M., Pan S., Jiang J., Zhang Y., Wang H., Chen J., Shen H. and Hu Z. 2012. Genetic variants in human leukocyte antigen/DP-DQ influence both hepatitis B virus clearance and hepatocellular carcinoma development. Hepatology 55: 1426-1431.

Hu Z., Liu Y., Zhai X., Dai J., Jin G., Wang L., Zhu L., Yang Y., Liu J., Chu M., Wen J., Xie K., Du G., Wang Q., Zhou Y., Cao M., Liu L., He Y., Wang Y., Zhou G., Jia W., Lu J., Li S., Yang H., Shi Y., Zhou W. and Shen H. 2013. New loci associated with chronic hepatitis B virus infection in Han Chinese. Nat Genet 45: 1499-1503.

Kamatani Y., Wattanapokayakit S., Ochi H., Kawaguchi T., Takahashi A., Hosono N., Kubo M., Tsunoda T., Kamatani N., Kumada H., Puseenam A., Sura T., Daigo Y., Chayama K., 
Li S., Qian J., Yang Y., Zhao W., Dai J., Bei J. X., Foo J. N., McLaren P. J., Li Z., Yang J., Shen 6p21.32 and 21q21.3 for hepatocellular carcinoma in chronic hepatitis B virus carriers. PLoS Genet 8: e1002791.

Li W., Jiang Y., Jin Q., Shi X., Jin J., Gao Y., Pan Y., Zhang H., Jiang J. and Niu J. 2011. Expression and gene polymorphisms of interleukin 28B and hepatitis B virus infection in a Chinese Han population. Liver Int 31: 1118-1126.

Liaw Y. F. and Chu C. M. 2009. Hepatitis B virus infection. Lancet 373: 582-592.

Martin-Carbonero L., Rallon N. I., Benito J. M., Poveda E., Gonzalez-Lahoz J. and Soriano V. 2012. Short communication: Does interleukin-28B single nucleotide polymorphisms influence the natural history of hepatitis B? AIDS Res Hum Retroviruses 28: 1262-1264.

Patin E., Kutalik Z., Guergnon J., Bibert S., Nalpas B., Jouanguy E., Munteanu M., Bousquet L., Argiro L., Halfon P., Boland A., Mullhaupt B., Semela D., Dufour J. F., Heim M. H., Moradpour D., Cerny A., Malinverni R., Hirsch H., Martinetti G., Suppiah V., Stewart G., Booth D. R., George J., Casanova J. L., Brechot C., Rice C. M., Talal A. H., Jacobson I. 
267

268

M., Bourliere M., Theodorou I., Poynard T., Negro F., Pol S., Bochud P. Y. and Abel L. 2012. Genome-wide association study identifies variants associated with progression of liver fibrosis from HCV infection. Gastroenterology 143: 1244-1252 e1241-1212.

Seto W. K., Wong D. K., Kopaniszen M., Proitsi P., Sham P. C., Hung I. F., Fung J., Lai C. L. and Yuen M. F. 2013. HLA-DP and IL28B polymorphisms: influence of host genome on hepatitis B surface antigen seroclearance in chronic hepatitis B. Clin Infect Dis 56: 1695 1703.

Song Y., Shen Y., Lu W., Xia X. and Zhang A. M. 2016. Analysis of Biochemical Features of Hepatitis B Virus Infected Patients in Southwest China. Clin Lab 62: 1803-1807.

Stattermayer A. F. and Ferenci P. 2015. Effect of IL28B genotype on hepatitis B and C virus infection. Curr Opin Virol 14: 50-55.

Stephens M. and Donnelly P. 2003. A comparison of bayesian methods for haplotype reconstruction from population genotype data. Am J Hum Genet 73: 1162-1169.

Sungkanuparph S., Vibhagool A., Manosuthi W., Kiertiburanakul S., Atamasirikul K., Aumkhyan A. and Thakkinstian A. 2004. Prevalence of hepatitis B virus and hepatitis C virus co-infection with human immunodeficiency virus in Thai patients: a tertiary-carebased study. J Med Assoc Thai 87: 1349-1354.

Suppiah V., Moldovan M., Ahlenstiel G., Berg T., Weltman M., Abate M. L., Bassendine M., Spengler U., Dore G. J., Powell E., Riordan S., Sheridan D., Smedile A., Fragomeli V., Muller T., Bahlo M., Stewart G. J., Booth D. R. and George J. 2009. IL28B is associated with response to chronic hepatitis $\mathrm{C}$ interferon-alpha and ribavirin therapy. Nat Genet 41: 
289

290

291

292

293

294

295

296

297

298

299

300

301

302

303

304

305

306

307

308

Tanaka Y., Nishida N., Sugiyama M., Kurosaki M., Matsuura K., Sakamoto N., Nakagawa M., Korenaga M., Hino K., Hige S., Ito Y., Mita E., Tanaka E., Mochida S., Murawaki Y., Honda M., Sakai A., Hiasa Y., Nishiguchi S., Koike A., Sakaida I., Imamura M., Ito K., Yano K., Masaki N., Sugauchi F., Izumi N., Tokunaga K. and Mizokami M. 2009. Genome-wide association of IL28B with response to pegylated interferon-alpha and ribavirin therapy for chronic hepatitis C. Nat Genet 41: 1105-1109.

Thomas D. L., Thio C. L., Martin M. P., Qi Y., Ge D., O'Huigin C., Kidd J., Kidd K., Khakoo S. I., Alexander G., Goedert J. J., Kirk G. D., Donfield S. M., Rosen H. R., Tobler L. H., Busch M. P., McHutchison J. G., Goldstein D. B. and Carrington M. 2009. Genetic variation in IL28B and spontaneous clearance of hepatitis C virus. Nature 461: 798-801.

Thompson A. J., Clark P. J., Singh A., Ge D., Fellay J., Zhu M., Zhu Q., Urban T. J., Patel K., Tillmann H. L., Naggie S., Afdhal N. H., Jacobson I. M., Esteban R., Poordad F., Lawitz E. J., McCone J., Shiffman M. L., Galler G. W., King J. W., Kwo P. Y., Shianna K. V., Noviello S., Pedicone L. D., Brass C. A., Albrecht J. K., Sulkowski M. S., Goldstein D. B., McHutchison J. G. and Muir A. J. 2012. Genome-wide association study of interferon-related cytopenia in chronic hepatitis C patients. $J$ Hepatol 56: 313-319.

Trepo C., Chan H. L. and Lok A. 2014. Hepatitis B virus infection. Lancet 384: 2053-2063.

Wasityastuti W., Yano Y., Ratnasari N., Triyono T., Triwikatmani C., Indrarti F., Heriyanto D. S., Yamani L. N., Liang Y., Utsumi T. and Hayashi Y. 2016. Protective effects of HLADPA1/DPB1 variants against Hepatitis B virus infection in an Indonesian population. 
310 Zhang A.-M., Ma K., Song Y., Wang B., Feng Y., Liu L. and Xia X. 2014. Genetic

311 polymorphisms of the IFNlambda genes are associated with biochemical features in Han 
317 Figure 1. Quantification of viral load in acute or chronic HBV-infected individuals. Each

318 sample is represented by one circle (for acute HBV infected individuals) or one square (for

319 chronic HBV infected individuals). The middle line in each group represents the mean number of 320 the HBV viral load, together with standard error of the group.

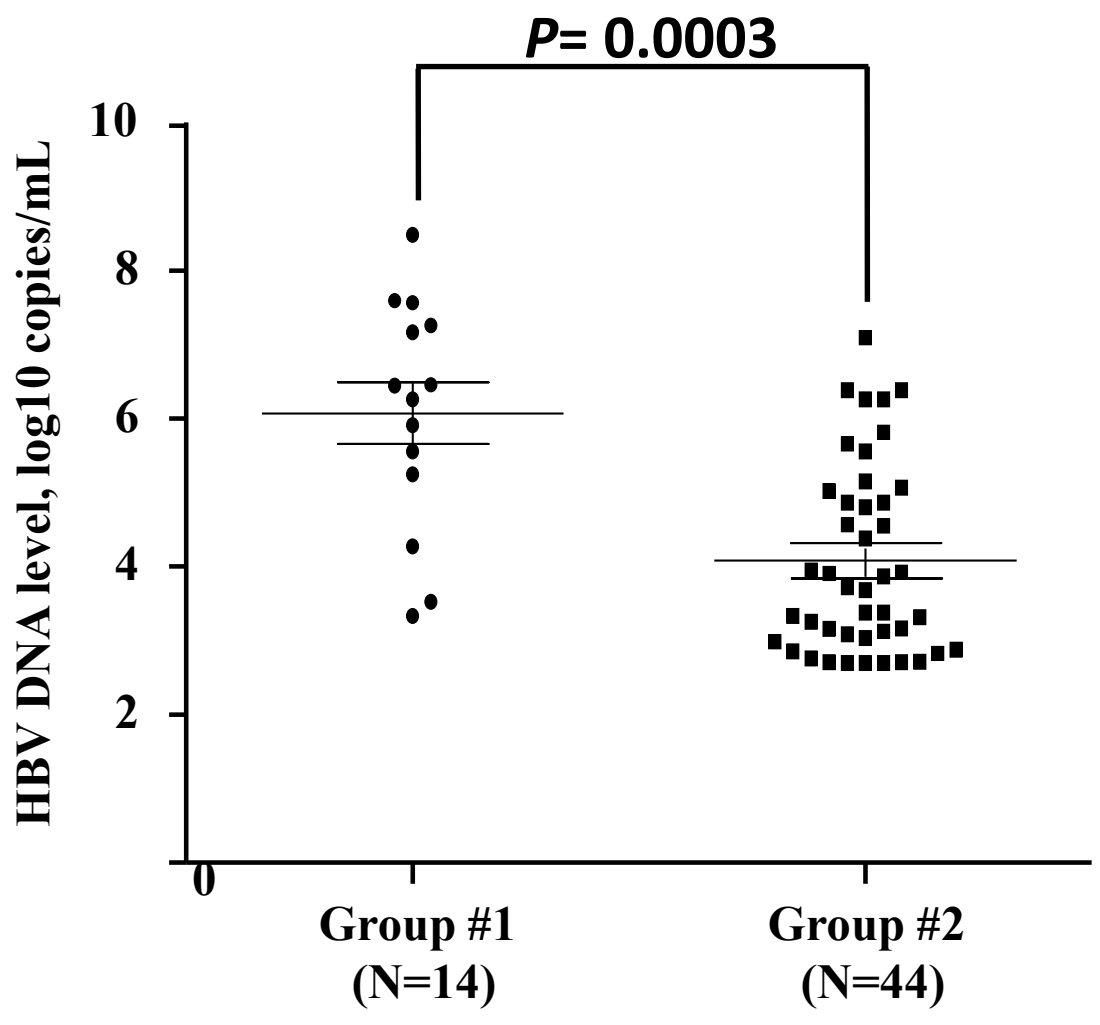


323 Table 1. genotype and allele frequency of three SNPs of the IL28B gene in HBV infected 324 individuals and controls

\begin{tabular}{|c|c|c|c|c|c|c|}
\hline \multicolumn{2}{|c|}{$\begin{array}{c}\text { SNP } \\
\text { (genotype/allele) }\end{array}$} & $\begin{array}{l}\text { HBV infected } \\
\text { individual } \\
\quad(\mathrm{N}=493)\end{array}$ & $\begin{array}{l}\text { Controls } \\
(\mathrm{N}=460)\end{array}$ & $P$ - value & OR & $95 \% \mathrm{CI}$ \\
\hline \multicolumn{2}{|c|}{ rs12979860 } & $\mathrm{HWE}^{\dagger} P=1.00$ & HWE $P=0.79$ & & & \\
\hline \multirow{3}{*}{ Genotype } & $\mathrm{CC}$ & 439 & 400 & 0.320 & 1.219 & $0.824-1.804$ \\
\hline & $\mathrm{CT}$ & 52 & 57 & 0.372 & 0.834 & $0.559-1.243$ \\
\hline & TT & 2 & 3 & 0.599 & 0.621 & $0.103-3.730$ \\
\hline \multirow{2}{*}{ Allele } & $\mathrm{C}$ & 930 & 857 & \multirow{2}{*}{0.292} & 1.221 & $0.842-1.771$ \\
\hline & $\mathrm{T}$ & 56 & 63 & & 0.819 & $0.565-1.188$ \\
\hline \multicolumn{2}{|c|}{ rs8099917 } & HWE $P=1.00$ & HWE $P=1.00$ & & & \\
\hline \multirow{3}{*}{ Genotype } & GG & 1 & 2 & 0.523 & 0.465 & $0.042-5.151$ \\
\hline & GT & 49 & 52 & 0.494 & 0.866 & $0.573-1.308$ \\
\hline & TT & 443 & 406 & 0.429 & 1.178 & $0.784-1.771$ \\
\hline \multirow{2}{*}{ Allele } & $\mathrm{G}$ & 51 & 56 & \multirow{2}{*}{0.386} & 0.842 & $0.570-1.244$ \\
\hline & $\mathrm{T}$ & 935 & 864 & & 1.188 & $0.804-1.756$ \\
\hline \multicolumn{2}{|c|}{ rs12980275 } & HWE $P=0.78$ & HWE $P=0.50$ & & & \\
\hline \multirow{3}{*}{ Genotype } & $\mathrm{AA}$ & 437 & 398 & 0.321 & 1.216 & $0.826-1.788$ \\
\hline & $\mathrm{AG}$ & 55 & 58 & 0.488 & 0.870 & $0.588-1.298$ \\
\hline & GG & 1 & 4 & 0.155 & 0.232 & $0.026-2.081$ \\
\hline \multirow{2}{*}{ Allele } & $\mathrm{A}$ & 929 & 854 & \multirow{2}{*}{0.216} & 1.260 & $0.873-1.817$ \\
\hline & $\mathrm{G}$ & 57 & 66 & & 0.794 & $0.550-1.145$ \\
\hline
\end{tabular}

$326 \dagger$ Chi-square test for deviation from the Hardy-Weinberg equilibrium (a value of $P<0.01$ was

327 regarded as a deviation from the HWE).

$328 \div$ Chi-square test was used. 
330 Table 2. Haplotypes constructed by three SNPs in HBV infected individuals and controls

\begin{tabular}{|c|c|c|c|c|c|}
\hline Haplotype & $\begin{array}{c}\text { HBV infected } \\
\text { individuals } \\
(\mathrm{N}=493)\end{array}$ & $\begin{array}{c}\text { Controls } \\
(\mathrm{N}=460)\end{array}$ & $P$-value $\ddagger$ & OR & $95 \%$ CI \\
\hline CTA & 925 & 853 & 0.339 & 1.191 & $0.832-1.706$ \\
\hline TGG & 46 & 55 & 0.201 & 0.770 & $0.515-1.151$ \\
\hline TTG & 7 & 7 & 0.896 & 0.933 & $0.326-2.669$ \\
\hline Others ${ }^{\dagger}$ & 8 & 5 & 0.478 & 1.497 & $0.488-4.592$ \\
\hline
\end{tabular}

331

$332 \dagger$ Means those haplotypes which frequency is less than $0.5 \%$.

$333 \mp$ Chi-square test was used. 
334 Table 3 Genotype and allele frequency in three groups of HBV infected individuals

\begin{tabular}{|c|c|c|c|c|c|c|c|}
\hline \multicolumn{2}{|c|}{$\begin{array}{c}\text { SNP } \\
\text { (Genotype/ Allele) }\end{array}$} & $\begin{array}{c}\text { Group \#1 } \\
(\mathrm{N}=29)\end{array}$ & $\begin{array}{l}\text { Group \#2 } \\
(\mathrm{N}=202)\end{array}$ & $\begin{array}{l}\text { Group \#3 } \\
(\mathrm{N}=262)\end{array}$ & $\begin{array}{l}\text { group \#1 v.s. group \#2 }{ }^{\dagger} \\
P \text {-value }(\mathrm{OR}, 95 \% \mathrm{CI})\end{array}$ & $\begin{array}{l}\text { group \#1 v.s. group \#3 } \\
P \text {-value (OR, } 95 \% \mathrm{CI}) \\
\end{array}$ & $\begin{array}{l}\text { group \#2 v.s. group \#3 } \\
P \text {-value (OR, } 95 \% \mathrm{CI}) \\
\end{array}$ \\
\hline \multicolumn{8}{|c|}{ rs12979860 } \\
\hline \multirow[t]{3}{*}{ Genotype } & $\mathrm{CC}$ & 24 & 178 & 237 & $0.415(0.647,0.226-1.856)$ & $0.196(0.506,0.178-1.444)$ & $0.416(0.782,0.432-1.415)$ \\
\hline & $\mathrm{CT}$ & 5 & 22 & 25 & $0.320(1.705,0.590-4.922)$ & $0.196(1.975,0.693-5.632)$ & $0.633(1.159,0.633-2.121)$ \\
\hline & $\mathrm{TT}$ & 0 & 2 & 0 & $0.590(-)$ & $1.000(-)$ & $0.107(-)$ \\
\hline \multirow[t]{2}{*}{ Allele } & $\mathrm{C}$ & 53 & 378 & 499 & $0.534(0.729,0.268-1.981)$ & $0.208(0.531,0.195-1.445)$ & $0.270(1.373,0.780-2.416)$ \\
\hline & $\mathrm{T}$ & 5 & 26 & 25 & $0.534(1.372,0.505-3.726)$ & $0.208(1.883,0.692-5.124)$ & $0.270(0.728,0.414-1.282)$ \\
\hline \multicolumn{8}{|l|}{ rs8099917 } \\
\hline \multirow[t]{3}{*}{ Genotype } & GG & 0 & 1 & 0 & $0.704(-)$ & $1.000(-)$ & $0.254(-)$ \\
\hline & GT & 6 & 21 & 22 & $0.107(2.248,0.822-6.147)$ & $0.033 *(2.846,1.048-7.728)$ & $0.462(1.266,0.675-2.372)$ \\
\hline & TT & 23 & 180 & 240 & $0.131(0.469,0.172-1.276)$ & $0.033 *(0.351,0.129-0.954)$ & $0.363(0.750,0.403-1.397)$ \\
\hline \multirow[t]{2}{*}{ Allele } & $\mathrm{G}$ & 6 & 23 & 22 & $0.172(1.911,0.744-4.913)$ & $0.038 *(2.633,1.022-6.786)$ & $0.293(1.377,0.756-2.509)$ \\
\hline & $\mathrm{T}$ & 52 & 381 & 502 & $0.172(0.523,0.204-1.345)$ & $0.038 *(0.380,0.147-0.979)$ & $0.293(0.726,0.399-1.322)$ \\
\hline \multicolumn{8}{|l|}{ rs 12980275} \\
\hline \multirow[t]{3}{*}{ Genotype } & AA & 24 & 177 & 236 & $0.466(0.678,0.237-1.939)$ & $0.226(0.529,0.186-1.504)$ & $0.402(0.780,0.436-1.397)$ \\
\hline & $\mathrm{AG}$ & 5 & 24 & 26 & $0.415(1.545,0.539-4.431)$ & $0.226(1.891,0.665-5.378)$ & $0.500(1.224,0.680-2.203)$ \\
\hline & GG & 0 & 1 & 0 & $0.704(-)$ & $1.000(-)$ & $0.254(-)$ \\
\hline \multirow[t]{2}{*}{ Allele } & $\mathrm{A}$ & 53 & 378 & 498 & $0.534(0.729,0.268-1.981)$ & $0.239(0.553,0.204-1.502)$ & $0.333(0.759,0.434-1.329)$ \\
\hline & G & 5 & 26 & 26 & $0.534(1.372,0.505-3.726)$ & $0.239(1.807,0.666-4.903)$ & $0.333(1.317,0.753-2.306)$ \\
\hline
\end{tabular}

$335 \dagger$ Chi-square test was used to calculate the $P$-value.

$336 \ddagger$ OR and 95\% CI mean Odds ratio and Confidence interval, respectively. 
Table 4. Analysis of biochemical characteristics of genotypes of each SNP in HCV-infected persons.

\begin{tabular}{|c|c|c|c|c|c|c|c|}
\hline \multirow{2}{*}{$\begin{array}{l}\text { Marke } \\
\text { r }\end{array}$} & \multicolumn{3}{|c|}{ rs12979860 $($ Mean \pm SEM $)$} & \multirow[t]{2}{*}{ Marker } & \multicolumn{3}{|c|}{ rs $12979860($ Mean \pm SEM $)$} \\
\hline & $\mathrm{CC}$ & $\mathrm{CT} \& \mathrm{TT}$ & $P$ - value ${ }^{\dagger}$ & & $\mathrm{CC}$ & CT \& TT & $P$-value \\
\hline AST & $38.86 \pm 4.29$ & $32.41 \pm 4.04$ & 0.598 & BUN & $5.15 \pm 0.19$ & $4.42 \pm 0.16$ & 0.168 \\
\hline ALT & $48.16 \pm 7.46$ & $36.02 \pm 5.22$ & 0.566 & CREA & $81.78 \pm 5.94$ & $63.09 \pm 2.08$ & 0.269 \\
\hline TBIL & $14.77 \pm 0.91$ & $12.85 \pm 0.73$ & 0.460 & UA & $344.9 \pm 5.05$ & $338.7 \pm 13.48$ & 0.683 \\
\hline DBIL & $6.48 \pm 0.71$ & $4.68 \pm 0.36$ & 0.371 & WBC & $9.26 \pm 2.47$ & $7.00 \pm 0.36$ & 0.749 \\
\hline IBIL & $8.28 \pm 0.26$ & $8.18 \pm 0.44$ & 0.890 & NEUT & $4.39 \pm 0.13$ & $4.36 \pm 0.35$ & 0.939 \\
\hline TP & $72.90 \pm 0.37$ & $72.89 \pm 0.87$ & 0.993 & LYM & $1.78 \pm 0.03$ & $2.00 \pm 0.10$ & 0.032 \\
\hline ALB & $40.54 \pm 0.29$ & $40.69 \pm 0.70$ & 0.865 & MONO & $0.42 \pm 0.01$ & $0.45 \pm 0.03$ & 0.333 \\
\hline GLOB & $32.36 \pm 0.26$ & $32.20 \pm 0.66$ & 0.843 & EO & $0.15 \pm 0.01$ & $0.12 \pm 0.01$ & 0.255 \\
\hline GLU & $4.90 \pm 0.07$ & $4.61 \pm 0.10$ & 0.152 & BASO & $0.03 \pm 0.001$ & $0.03 \pm 0.003$ & 0.948 \\
\hline \multirow{2}{*}{$\begin{array}{l}\text { Marke } \\
\text { r }\end{array}$} & \multicolumn{3}{|c|}{ rs8099917 $($ Mean \pm SEM $)$} & Marker & \multicolumn{3}{|c|}{ rs8099917 $($ Mean \pm SEM $)$} \\
\hline & GG \& GT & TT & $P$-value & & GG \& GT & TT & $P$-value \\
\hline AST & $31.48 \pm 3.92$ & $38.91 \pm 4.26$ & 0.557 & BUN & $4.43 \pm 0.16$ & $5.15 \pm 0.19$ & 0.198 \\
\hline ALT & $36.68 \pm 5.60$ & $47.98 \pm 7.39$ & 0.606 & CREA & $64.40 \pm 2.26$ & $81.46 \pm 5.88$ & 0.329 \\
\hline TBIL & $13.69 \pm 0.96$ & $14.66 \pm 0.90$ & 0.719 & UA & $347.8 \pm 14.26$ & $343.8 \pm 5.02$ & 0.799 \\
\hline DBIL & $4.93 \pm 0.40$ & $6.44 \pm 0.70$ & 0.471 & WBC & $6.89 \pm 0.32$ & $9.25 \pm 2.45$ & 0.747 \\
\hline IBIL & $8.86 \pm 0.63$ & $8.21 \pm 0.25$ & 0.481 & NEUT & $4.31 \pm 0.27$ & $4.40 \pm 0.13$ & 0.827 \\
\hline TP & $73.16 \pm 0.90$ & $72.87 \pm 0.37$ & 0.797 & LYM & $1.98 \pm 0.10$ & $1.79 \pm 0.03$ & 0.075 \\
\hline
\end{tabular}




\begin{tabular}{|c|c|c|c|c|c|c|c|}
\hline ALB & $41.04 \pm 0.66$ & $40.50 \pm 0.29$ & 0.544 & MONO & $0.46 \pm 0.03$ & $0.42 \pm 0.01$ & 0.186 \\
\hline GLOB & $32.12 \pm 0.68$ & $32.37 \pm 0.26$ & 0.760 & $\mathrm{EO}$ & $0.12 \pm 0.02$ & $0.15 \pm 0.01$ & 0.264 \\
\hline GLU & $4.55 \pm 0.09$ & $4.90 \pm 0.07$ & 0.091 & BASO & $0.03 \pm 0.003$ & $0.03 \pm 0.001$ & 0.903 \\
\hline \multirow{2}{*}{$\begin{array}{l}\text { Marke } \\
\text { r }\end{array}$} & \multicolumn{3}{|c|}{ rs12980275 $($ Mean \pm SEM $)$} & Marker & \multicolumn{3}{|c|}{ rs $12980275($ Mean \pm SEM $)$} \\
\hline & $\mathrm{AA}$ & AG \& GG & $P$-value & & AA & $\mathrm{AG} \& \mathrm{GG}$ & $P$-value \\
\hline AST & $38.92 \pm 4.31$ & $32.20 \pm 3.89$ & 0.577 & BUN & $5.16 \pm 0.19$ & $4.43 \pm 0.16$ & 0.166 \\
\hline ALT & $48.29 \pm 7.49$ & $35.48 \pm 5.05$ & 0.539 & CREA & $81.89 \pm 5.96$ & $62.95 \pm 1.92$ & 0.255 \\
\hline TBIL & $14.75 \pm 0.92$ & $13.09 \pm 0.72$ & 0.517 & UA & $345.5 \pm 5.13$ & $334.3 \pm 11.71$ & 0.454 \\
\hline DBIL & $6.49 \pm 0.71$ & $4.70 \pm 0.34$ & 0.368 & WBC & $9.27 \pm 2.48$ & $6.97 \pm 0.34$ & 0.741 \\
\hline IBIL & $8.25 \pm 0.26$ & $8.40 \pm 0.44$ & 0.847 & NEUT & $4.39 \pm 0.13$ & $4.34 \pm 0.34$ & 0.895 \\
\hline TP & $72.85 \pm 0.38$ & $73.27 \pm 0.83$ & 0.669 & LYM & $1.78 \pm 0.03$ & $2.00 \pm 0.10$ & 0.034 \\
\hline ALB & $40.50 \pm 0.29$ & $40.96 \pm 0.69$ & 0.585 & MONO & $0.42 \pm 0.01$ & $0.45 \pm 0.03$ & 0.384 \\
\hline GLOB & $32.35 \pm 0.27$ & $32.30 \pm 0.62$ & 0.956 & $\mathrm{EO}$ & $0.15 \pm 0.01$ & $0.12 \pm 0.01$ & 0.341 \\
\hline GLU & $4.90 \pm 0.07$ & $4.64 \pm 0.10$ & 0.194 & BASO & $0.03 \pm 0.001$ & $0.03 \pm 0.002$ & 0.859 \\
\hline
\end{tabular}

$\dagger$ Student $t$ test (unpaired, two-tail) was used 